\title{
Comment
}

\section{Scoping the shape of an iceberg: the future of public involvement in heath policy: reflecting on 'Public involvement policies in health: exploring their conceptual basis'}

\author{
COLLEEN M. FLOOD*
}

Faculty of Law, Common Law Section, University of Ottawa Research Chair in Health Law \& Policy, Canada

Writing in HEPL in 2006, Wait and Nolte scoped out the vague conceptual framework and hazy research base of public involvement in health policy. In doing so, they highlighted:

1. that the meaning of the term 'public' has not been clearly defined, and is used in differing ways across decision-making contexts;

2. that little is known about the motivations and impact of individuals assuming the mantle of 'public' in different decision-making contexts;

3. that there is no firm theoretical foundation specifying the rationale for involving the public in decision making; and

4. that attempts to evaluate the impact of public involvement in decision making raise a host of methodological challenges.

Over the past nine years, the science of public participation has evolved, but still problems of definition and clarity bedevil the field, underscoring the essential problem of a lack of a firm theoretical foundation. Asked for a candid assessment, leading Canadian expert Julia Abelson concedes that the field is still very much in its nascence - with progress over the past decade consisting mainly of clarifying the conceptual terrain, and articulating the myriad challenges involved in defining and achieving 'high-quality' public participation. Despite the limited research base, senior decision makers want evidence that public participation makes a difference and evidence as how to best implement public participation in decision making. In what follows, I provide a few reflections on this field, arguing that public participation confers legitimacy on public institutions, quite independently of its quantifiable impact on policy making, but this means that there are great dangers associated with insincere or ineffectual attempts at public participation.

\footnotetext{
*Correspondence to: Professor Colleen M. Flood, University of Ottawa Research Chair in Health Law \& Policy, University of Ottawa, Faculty of Law - Common Law Section, 57 Louis Pasteur, Ottawa Ontario, K1N 6N5 Canada. Email: cflood@uottawa.ca
} 
I further contend that whilst public participation is important even if the process does not have a measurable impact in terms of outcomes, it is still important to advance the science by measuring the quality of public participation. Finally, I point out that - in the Canadian context at least - whilst we genuflect at the altar of public participation, it is rare to find real examples of including the public in actual decision making.

With respect to theoretical foundations, public involvement in decision making should be seen as an end in and of itself. Publicly funded health care systems are created by the people for the people. The theoretical foundation for including the public in decision making is that this contributes to the legitimacy of public health care systems qua public institution. The public should be deeply involved in decision-making structures in many guises - informing and participating in priority setting, but also to inform and shape the development of health policy more broadly. The rise of patient rights, patient-centered care and attempts to develop 'choice' within publicly funded systems are close cousins to the concept of including the public in policy making. They all speak to the aspiration of ensuring the legitimacy and accountability of public health care systems. Take, for example, the existence of a high-performing health agency like New Zealand's Pharmac that within a fixed budget actively prioritizes the drugs that it provides to the population on the basis of cost-effectiveness. Although involving the public in decision making may not necessarily change the outcome of a particular decision, excluding the public from decision making would, in my view, mean that organizations like Pharmac would not survive politically.

My commitment to the idea that public participation is inherently valuable even if one can't immediately discern an impact upon policy, perhaps, is a result of my legal training. A core principle of administrative law, procedural fairness, requires governmental decision makers to comply with basic principles of natural justice, notably the principle that people are entitled to a fair hearing when decisions are being made that impact them. The same should be said of including the public and patients in decision making throughout the entire health care system, simply as a matter of course. Without transparency and opportunities for public input, even otherwise sound decisions have an air of illegitimacy.

Much of my scholarship in recent years has focused on one specific forum of public participation in health policy making: the courts. A recent study found that $40 \%$ of the world's constitutions now recognize litigable rights to health or health care (Jung et al., 2014). Celebrants of this trend contend that "[r]ights ensure services for the most marginalised and vulnerable populations, making it hard to claim progress by reference to numerical aggregates" (Sidibé and Buse, 2013). A small but growing body of legal scholarship has sought to ascertain whether this hope for health rights is borne out by the evidence (Yamin and Gloppin, 2011; Flood and Gross, 2014). As with efforts to measure the impact of public participation on health policy generally, researchers have struggled mightily in their effort to 'prove' the impact of health rights litigation. Similar to the challenges 
diagnosed by Wait and Nolte, there are differing views as to the theoretical foundations of health rights, and the empirical evidence varies from country to country.

There are obvious concerns with the courts asserting themselves as a channel for plaintiffs to challenge health policy. A basic concern is that most people are barred from participating by the high cost of litigation; there is evidence, for example, that Brazil's right to health has had a regressive effect, allowing wealthier patients to secure access to expensive medicines (Ferraz, 2011). In some instances, rights are asserted that seem to run counter to the public interest: in Chaoulliv. Quebec, a groundbreaking 2005 decision from the Supreme Court of Canada, plaintiffs asserted their constitutional rights to life and security of the person to overturn a prohibition on parallel private insurance - jeopardizing a pillar of the country's one-tier health care system. The global move toward justiciable health rights is, one might argue, a misdirected attempt at ensuring the legitimacy of health systems, by offering individuals the opportunity to plead their case and hold governments accountable when their interests are affected by health policy. As I've indicated, I embrace this basic criterion of legitimacy, but I have misgivings about the courts as a venue. Research into the issues identified by Wait and Nolte provides valuable context for this debate among legal scholars. By gaining a clearer understanding of what good public participation looks like, we are in a better position to evaluate the courts' contributions.

In arguing that public participation is valuable, independent of its impact on outcomes, I am not thus suggesting that all participatory processes are of a piece: there are better and worse ways to go about this, and there is a need for some objective criteria of evaluation. Without a clear, measurable understanding of how the public is best included, engaged or consulted in a particular context, the process can be subject to manipulation. In a worst-case scenario, governments may simply trot out non-substantive attempts at public engagements - with the paternalistic notion that a spoonful of public participation will help the medicine go down! In this regard, Wait and Nolte quote Cayton (2003), “[are we] engaged in a radical rethinking of the relationship between health care providers and the people who pay for them or are we just trying to use patient [and public] compliance to manage the system better?" (Wait and Nolte, 2006: 159). This is of great concern as public engagement and consultation that is not meaningful will undermine rather than strengthen the legitimacy of a public health care system. As research experts, we should take a zero-tolerance approach to cynical attempts at heading off critical public commentary on policy changes by way of token public input, exposing those organizing and individuals that do so and refusing to be part of any such process.

At the international level, the Organization for Economic Co-Operation and Development (OECD) finds that “... there is a striking imbalance between the amount of time, money and energy that governments in OECD countries invest in engaging citizens and civil society in public decision making and the amount of attention they pay to evaluating the effectiveness and impact of such efforts" 
(OECD, 2005: 10). As argued above, I do not think the theoretical basis for this field demands demonstration of immediate policy impact, but subsequent research must rigorously scrutinize whether and to what extent attempts at public engagement are meaningful and to what extent they allow for the flow of the insights, information and values that the public can provide.

Let me also mention a word on the growing complexity of this challenge. Since 2006, it seems there has been significant growth in the means and models for public participation. A scoping review commissioned by Alberta Health Services found some 15 different terms and definitions for patient engagement, 17 engagement models and 34 toolkits for patient engagement and evaluation initiatives (Kovacs Burns et al., 2014). This growing range and complexity of tools and methods in my mind is not symbolic of disorganization in the field. As I mentioned above, the public needs to be inculcated in decision making in many different ways throughout the health care system. Thus, the growing complexity of the field reflects the depth, breadth and range of what needs to be done to engage the public in decision making in public health care systems. Moreover, we likely have only scoped the tip of the iceberg in this regard. The present range of tools and methods are generally very traditional and don't yet employ the varied modes of social media possible to engage the public and patients. Of course, the communication revolution can be over-hyped, but there is at least an enormous potential to expand avenues of public participation and to reduce the cost thereof.

On a final note, Wait and Nolte point to Canada as an example of a jurisdiction that has embraced public participation in decision making. This, in my view, is not the case. Where Canada has made a concerted effort to include the public, it has most notably been for the purposes of writing (yet another) report on the health care system and how to fix it (e.g. the Romanow Commission, see Maxwell et al., 2003). As commendable as these efforts are, they are several degrees of separation away from actual engagement in policy making. Public involvement is valued in theory, but too frequently sacrificed upon an altar of pragmatism: getting the public involved is considered too complex, too time consuming, too costly and its benefits too nebulous. In contrast, stakeholders - particularly those representing the interest and expertise of health care providers - are nearly always assured a place at the table. Although Canadian scientists (Charles and Demaio, 1993; Lomas, 1997; Thurston et al., 2005; Abelson et al., 2010, 2013a, 2013b; Boivin et al., 2014) have made many important contributions, the actual practice of engaging the public in decision making has many miles to go.

\section{Acknowledgements}

The author would like to thank Bryan Thomas for his assistance with this article, and Professor Julia Abelson for her insights and reflections on this piece. 


\section{References}

Abelson, J., S. Montesanti, K. Li, F.-P. Gauvin and E. Martin (2010), Effective Strategies for Interactive Public Engagement in the Development of Healthcare Policies and Programs, Ottawa: Canadian Health Services Research Foundation.

Abelson, J., Y. Bombard, F.-P. Gauvin, D. Simeonov and S. E. Boesveld (2013a), 'Assessing the impacts of citizen deliberations on the health technology process', International Journal of Technology Assessment in Health, 29(3): 282-289.

Abelson, J., E. A. Blacksher, K. K. Li, S. E. Boesveld and S. D. Goold (2013b), 'Public deliberation in health policy and bioethics: mapping an emerging, interdisciplinary field', Journal of Public Deliberation, 9(1): article 5, 1-35. http://www.publicdeliberation.net/jpd/vol9/iss1/art5 [31 March 2015].

Boivin, A., P. Lehoux, R. Lacombe, J. Burgers and R. Grol (2014), 'Involving patients in setting priorities for healthcare improvement: a clustered randomized trial', Implementation Science, 9: 24.

Charles, C. A. and S. DeMaio (1993), 'Lay participation in health care decision-making: a conceptual framework', Journal of Health Politics, Policy and Law, 18(4): 881-904.

Ferraz, O. L. M. (2011), 'Harming the poor through social rights litigation: lessons from Brazil', Texas Law Review, 89: 1643-1668.

Flood, C. and A. Gross (eds) (2014), The Right to Health at the Public/Private Divide: A Global Comparative Study, New York, NY: Cambridge University Press.

Jung, C., R. Hirschl and E. Rosevear (2014), 'Economic and social rights in national constitutions', American Journal of Comparative Law, 62(4): 1043-1094.

Kovacs Burns, K., M. Bellows, C. Eigensher and J. Gallivan (2014), “Practical” resources to support patient and family engagement in healthcare decisions: a scoping review', $B M C$ Health Services Research, 14: 175.

Lomas, J. (1997), 'Reluctant rationers: public input to health care priorities', Journal of Health Services Research \& Policy, 2(2): 103-111.

Maxwell, J., S. Rosell and P. G. Forest (2003), 'Giving citizens a voice in healthcare policy in Canada', BMJ, 326(7397): 1031-1033.

Organization for Economic Co-Operation and Development (OECD). (2005), Evaluating Public Participation in Policy-Making, Paris: OECD.

Sidibé, M. and K. Buse (2013), 'Global health governance after 2015 - Authors' reply', The Lancet, 382: 1018-1019.

Thurston, W. E., G. MacKean, A. Vollman, A. Casebeer, M. Weber, B. Maloff and J. Bader (2005), 'Public participation in regional health policy: a theoretical framework', Health Policy, 73(3): 237-252.

Wait, S. and E. Nolte (2006), 'Public involvement policies in health: exploring their conceptual basis', Health Economics, Policy and Law, 1: 149-162.

Yamin, A. E. and S. Gloppen (eds) (2011), Litigating Health Rights: Can Courts Bring More Justice to Health? Cambridge, MA: Harvard University Press. 